\title{
SISTEM PENDUKUNG KEPUTUSAN KELAYAKAN PENERIMAAN NASABAH MENGGUNAKAN METODE PROFILE MATCHING
}

\author{
Anita Ahmad Kasim¹, Raziyan Dwi Pathan², \\ ${ }^{1,2}$ Universitas Tadulako, Palu, Sulawesi Tengah, Indonesia \\ ${ }^{1}$ nita.kasim@gmail.com, ${ }^{2}$ ziyan04indonesia@gmail.com,
}

\begin{abstract}
Abstrak-PT Sarana Sulteng Ventura merupakan salah satu perusahaan yang bertujuan untuk memberikan pinjaman modal Usaha Mikro, Kecil, dan Menengah (UMKM) sebagai pasangan usaha yang berjangka waktu pendek maupun panjang agar dapat berdiri sendiri dengan pinjaman modal yang sesuai dengan jenis usaha yang dibutuhkan bagi para nasabah. Dalam memberikan pinjaman modal usaha, perusahaan memiliki beberapa ketentuan dan persyaratan yang berlaku. dan perusahaan tersebut masih mengolah data nasabah secara manual sehingga dibutuhkan waktu cukup lama. Maka dengan ini penulis membuat sistem pendukung keputusan kelayakaan penerimaan nasabah yang akan memudahkan staff karyawan PT. Sarana Sulteng Ventura untuk menyeleksi nasabah layak menerima pinjaman modal usaha ke Nasabah atau UMKM. Sistem yang digunakan peneliti yaitu sistem berbasis web dengan menggunakan bahasa pemrograman PHP dan MySQL menjadi mengolah basis datanya dan sublime text 2 sebagai editor dari Bahasa pemrograma. Pada penelitian ini digunakan metode profile matching untuk melakukan proses perhitungan penilaian untuk membantu memberikan keputusan kelayakan penerimaan nasabah pada PT. Sarana Sulteng Ventura Kota Palu.
\end{abstract}

Kata Kunci-Nasabah, Sistem Pendukung Keputusan, Metode Profile Matching.

Abstract-PT Sarana Sulteng Ventura is one company that aims to provide loan capital is micro, small, and medium enterprises (UMKM) as a venture partner timed short or long to be able to stand on its own with loan capital that fits with the kind of effort that it takes for the customer. In providing venture capital loans, the company has some terms and conditions that apply. and the company still cultivate customer data manually so that it takes quite a long time. Then with this author makes the eligibility decision support system which will facilitate customer acceptance staff employees of PT Sarana Sulteng Ventura to pre-screen customer deserves a loan business capital to client or small medium enterprises. The researchers used a system that is web-based systems using the programming language PHP and MySQL into its data base processing and sublime text 2 as editor of programming languages. This research used the method of profile matching process to perform the calculation of assessments to help give the eligibility decision of acceptance the customer at PT. Sarana Sulteng Ventura city of Palu.

Keywords-Customer, Decision support system, A Method of Profile Matching.

\section{PENDAHULUAN}

Nasabah ialah seorang peminjam modal dalam mengembangkan sebuah usaha yang dimilikinya. Untuk melancarkan kegiatan usahanya, nasabah harus mempunyai modal awal dalam mendirikan usahanya serta melihat perkembangan usahanya dalam waktu minimal 1 tahun untuk menghitung keuntungan yang diperoleh nasabah dan dapat mengembalikan pinjaman modal usahanya tersebut. Nasabah dalam melakukan kegiatan usahanya juga membutuhkan layanan yang lebih cepat dalam peminjaman modal usaha yang sudah berkembang pesat. Dan salah satu usaha yang dilakukan ialah UMKM yaitu Usaha Mikro, Kecil dan Menengah. Ketika usaha berkembang lebih maju, UMKM tersebut juga dapat melakukan peminjaman yang lebih besar.

PT Sarana Sulteng Ventura yang merupakan cabang dari Perusahaan Modal Ventura Daerah lndonesia yang didirikan pada tanggal 23 maret 1997. PT Sarana Sulteng Ventura merupakan salah satu perusahaan yang bertujuan untuk memberikan pinjaman modal Usaha Mikro, Kecil, dan Menengah (UMKM) sebagai pasangan usaha yang berjangka waktu pendek maupun panjang agar dapat berdiri sendiri dengan pinjaman modal yang sesuai dengan jenis usaha yang dibutuhkan bagi para nasabah.

Namun dalam memberikan pinjaman modal usaha, perusahaan PT Sarana Sulteng Ventura memiliki beberapa ketentuan dan persyaratan yang berlaku untuk memilih nasabah dan perusahaan tersebut masih 
mengolah data nasabah secara manual sehingga dibutuhkan waktu yang cukup lama. Adapun persyaratan yang dimaksud ialah penyeleksian kelayakan nasabah berdasarkan berkas administrasi dan kriteria nasabah tersebut.

Page | 99

\section{TINJAUAN PUSTAKA}

\section{A. Tinjauan Pustaka}

Penelitian yang sebelumnya pernah dilakukan sehubungan dengan sistem pendukung keputusan antara lain adalah :

1. Penelitian [1] Victor dkk (2014) yaitu Perangkat Lunak Pendukung Keputusan Kelayakan Calon Nasabah Pembiayaan Mikro Di Bank Syariah Mandiri Cabang Bandung Ahmadyani Menggunakan Metode Profile Matching. Penelitian tersebut dilakukan bertujuan untuk menyelesaikan proses pengajuan calon pembiyaan nasabah mikro lebih efektif \& efesien. Masalah dalam penelitan ini adalah Prosedur yang tidak mangkus atau tidak sesuai dengan aturan yang ada di bank Syariah mandiri cabang bandung ahmadyani sehingga dibuat perangkat lunak pendukung keputusan kelayakan calon nasabah pembiayaan mikro.

2. Penelitian [2] Nuraeni dkk (2015) yaitu pembuatan Sistem Pengambilan Keputusan Pemberian Kredit Usaha Rakyat (KUR) Menggunakan Metode Weighted Product (Studi Kasus : PT. BPR Arta Jaya Mandiri Tasikmalaya). Penelitian tersebut bertujuan untuk menentukan kelayakan terhadap nasabah yang layak menerima KUR sebagai mendukung kerja seorang manajer maupun sekelompok manajer dalam memecahkan masalah semi terstruktur dengan cara memberi informasi ataupun usulan menuju pada keputusan tertentu. Masalah penelitian ini ialah semakin tingginya minat masyarakat untuk mendapatkan KUR dan proses penentuan kelayakan penerima KUR masih menggunakan metode perbandingan antara pendapatan/bulan dengan kebutuhan/bulan.

3. Penelitian [3] Yusup (2015) yaitu Sistem Pendukung Keputusan Kelayakan Pemberian Kredit Pada Nasabah Dengan Metode Simple Additive Weighting (Studi Kasus PT. BPRS Al Wahliyah Medan. Penelitian tersebut dilakukan bertujuan Membantu Direksi PT. BPRS Al Washliyah dalam menentukan layak atau tidaknya kredit yang akan diberikan pada calon nasabah dengan melihat variabel-variabel yang mempengaruhi keputusan. Masalah pada penelitian ini yaitu bank dituntut untuk dapat mengambil keputusan dengan cepat dan cermat mengingat lingkungan bisnis perbankan yang semakin kompetitif dalam menentukan calon nasabah sehinggan dibuat sistem pendukung keputusan pemberian kredit pada nasabah.
4. Penelitian [4] Masrizal (2016) yaitu Sistem Pendukung Keputusan Kelayakan Pemberian Kredit Pada PT. Adira Quantum Dumai Dengan Metode Simple Additive Weighting (SAW) Menggunakan Bahasa Pemrograman Visual Basic 6.0. Penelitian tersebut dilakukan bertujuan untuk memenuhi kebutuhan dan keinginan masyarakat secara cepat yang membantu konsumen untuk memiliki barangbarang berkualitas tinggi melalui fasilitas cicilan tetap dan terjangkau. Masalah dalam penelitian ini ialah penentuan keputusan sering tidak sesuainya nasabah yang mendapatkan kredit sesuai dengan nilai kriteria dan nilai bobot yang ditentukan oleh perusahaan, lamanya penyerahan laporan keputusan kepada kepala perusahaan dan informasi kepada nasabah membuat lambatnya proses penentuan keputusan calon nasabah penerima kredit.

\section{METODE PENELITIAN}

\section{Profile Matching}

Metode profile matching atau pencocokan profil adalah metode yang sering sebagai mekanisme dalam pengambilan keputusan dengan mengasumsikan bahwa terdapat tingkat variabel prediktor yang ideal yang harus dipenuhi oleh subyek yang diteliti, bukannya tingkat minimal yang harus dipenuhi atau dilewati (Rosadi, 2015).

Dalam proses profile matching secara garis besar merupakan proses membandingkan antara nilai data aktual dari suatu profile yang akan dinilai dengan nilai profil yang diharapkan, sehingga dapat diketahui perbedaan kompetensinya (disebut juga gap), semakin kecil gap yang dihasilkan maka bobot nilainya semakin besar yang berarti memiliki peluang lebih besar untuk direkomendasikan untuk terpilih.

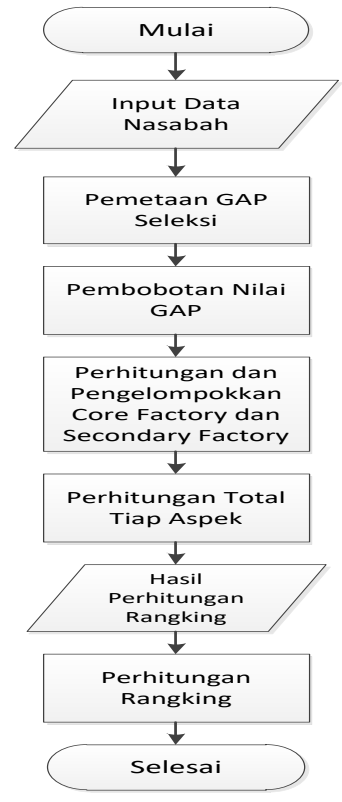

Gbr. 1 Flowchart Metode Profile Matching 
Page $\mid 100$

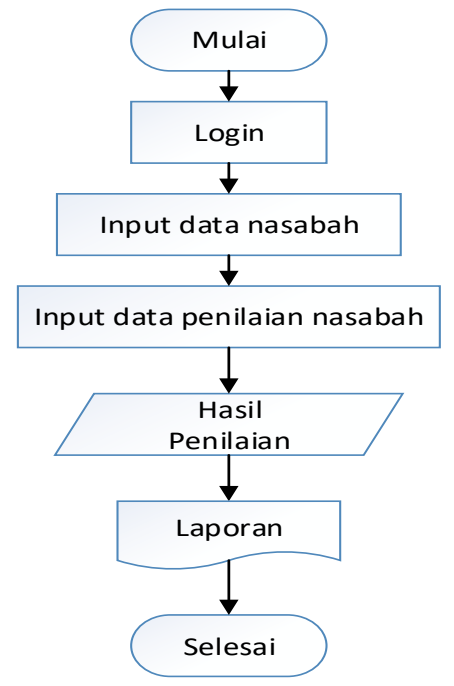

Gbr. 2 Flowchart Sistem Pendukung Keputusan Kelayakaan Penerimaan Nasabah.

Berikut adalah beberapa tahapan dan perumusan perhitungan dengan metode profile matching :

1. Pembobotan

Pada tahap ini, akan ditentukan bobot nilai masing-masing aspek dengan menggunakan bobot nilai yang telah ditentukan bagi masing-masing aspek itu sendiri. Pemberian pembobotan sendiri diberikan seuai dengan aspek dan kriteria pada sebuah kasus tertentu, contoh dalam pembobotan dapat dilihat pada Tabel 1.

TABEL I

PENILAIAN BOBOT GAP

\begin{tabular}{|c|c|c|l|}
\hline No. & Selisi & Bobot & \multicolumn{1}{|c|}{ Ket. } \\
\hline 1. & 0 & 4 & $\begin{array}{l}\text { Tidak ada selisih (kompetensi sesuai dengan yang } \\
\text { dibutuhkan) }\end{array}$ \\
\hline 2. & 1 & 4,5 & Kompetensi individu kelebihan 1 tingkat/level \\
\hline 3. & -1 & 3,5 & Kompetensi individu kekurangan 1 tingkat/level \\
\hline 4. & 2 & 6 & Kompetensi individu kelebihan 2 tingkat/level \\
\hline 5. & -2 & 3 & Kompetensi individu kekurangan 2 tingkat/level \\
\hline
\end{tabular}

2. Pemetaan Gap Kompetensi

Gap merupakan alat yang digunakan untuk mengevaluasi. Metode ini merupakan salah satu metode yang umum digunakan dalam pengelolaan manajemen suatu lembaga. Secara harfiah kata "gap" mengidentifikasikan adanya suatu perbedaan (Disparity) antara suatu hal dengan hal yang lain, Sehingga dari kedua aspek dapat kita hitung GAP untuk masing-masing aspek.

Contoh perhitungan profile matching sebagai berikut :

a. Penentuan penyeleksian dari beberapa aspek/kriteria menentukan kelayakan penerimaan nasabah dalam pemberian modal ke UMKM. Aspek penilaian yaitu:

1. Aspek Kelengkapan Berkas

a. Kartu Tanda Penduduk/KTP

b. Kartu Keluarga/KK c. Surat Keterangan Usaha

2. Aspek Jaminan
a. Jaminan Bangunan
b. Jaminan Tanah
c. Jaminan Motor
d. Jaminan Mobil

b. Penentuan nilai target dapat dilihat pada tabel 2 .

TABEL II

PENENTUAN NILAI TARGET

\begin{tabular}{|c|c|c|c|c|c|c|c|c|}
\hline No. & Nama & \multicolumn{3}{|c|}{$\begin{array}{c}\text { Aspek Kelengkapan } \\
\text { Berkas }\end{array}$} & \multicolumn{5}{c|}{ Aspek Jaminan } \\
\hline \multicolumn{2}{|c|}{ Sub Aspek } & $\begin{array}{c}\text { A } \\
\text { (KTP) }\end{array}$ & $\begin{array}{c}\text { B } \\
\text { (KK) }\end{array}$ & $\begin{array}{c}\text { C } \\
\text { (SKU) }\end{array}$ & $\begin{array}{c}\text { D } \\
\text { (JB) }\end{array}$ & $\begin{array}{c}\text { E } \\
\text { (JT) }\end{array}$ & $\begin{array}{c}\text { F } \\
\text { (JRD) }\end{array}$ & $\begin{array}{c}\text { G } \\
\text { (JRE) }\end{array}$ \\
\hline 1. & Nurhayati & 1 & 2 & 2 & 3 & 1 & 1 & 2 \\
\hline 2. & $\begin{array}{c}\text { Ahmad } \\
\text { Hadi }\end{array}$ & 2 & 2 & 2 & 1 & 2 & 1 & 1 \\
\hline 3. & Sulastri & 1 & 1 & 2 & 2 & 2 & 1 & 1 \\
\hline
\end{tabular}

Ket. Penilaian aspek kelengkapan berkas (KTP, KK, SKU)

Nilai $1=$ tidak ada

Nilai $2=$ ada

Ket. Penilaian aspek jaminan (JB, JT, JRT, JRE)

Nilai 1 = tidak lengkap, kecil, sempit, rendah

Nilai 2 = lengkap, sedang

Nilai 3 = sangat lengkap, besar, luas, tinggi

c. Pemetaan GAP untuk setiap sub aspek

$$
\mathrm{NCF}=\frac{\sum N C}{\sum I C} \mathrm{NSC}=\frac{\sum N C}{\sum I C}
$$

TABEL III

PEMETAAN GAP UNTUK SETIAP SUB ASPEK

\begin{tabular}{|c|c|c|c|c|c|c|c|c|}
\hline \multirow[t]{2}{*}{ No. } & \multirow{2}{*}{$\begin{array}{r}\text { Nama } \\
\text { Sub Aspek }\end{array}$} & \multicolumn{3}{|c|}{$\begin{array}{c}\text { Aspek Kelengkapan } \\
\text { Berkas }\end{array}$} & \multicolumn{4}{|c|}{ Aspek Jaminan } \\
\hline & & $\begin{array}{c}\text { A } \\
\text { (KTP) }\end{array}$ & $\begin{array}{c}\mathrm{B} \\
(\mathrm{KK})\end{array}$ & $\begin{array}{c}\mathrm{C} \\
(\mathrm{SKU})\end{array}$ & $\begin{array}{l}\mathrm{D} \\
\text { (JB) }\end{array}$ & $\begin{array}{l}\mathrm{E} \\
\text { (JT) }\end{array}$ & $\begin{array}{c}\mathrm{F} \\
\text { (JRD) }\end{array}$ & $\begin{array}{c}\mathrm{G} \\
\text { (JRE) }\end{array}$ \\
\hline 1. & Nurhayati & 1 & 2 & 2 & 3 & 1 & 1 & 2 \\
\hline 2. & Ahmad Hadi & 2 & 2 & 2 & 1 & 2 & 1 & 1 \\
\hline 3. & Sulastri & 1 & 1 & 2 & 2 & 2 & 1 & 1 \\
\hline \multicolumn{2}{|c|}{ Nilai Standar } & 2 & 2 & 2 & 3 & 3 & 3 & 3 \\
\hline 1. & Nurhayati & -1 & 0 & 0 & 0 & -2 & -2 & -1 \\
\hline 2. & Ahmad Hadi & 0 & 0 & 0 & -2 & -1 & -2 & -2 \\
\hline 3. & Sulastri & -1 & -1 & 0 & -1 & -1 & -2 & -2 \\
\hline \multicolumn{9}{|c|}{$\frac{1}{\text { Konversi Nilai Bobot }}$} \\
\hline 1. & Nurhayati & 3,5 & 4 & 4,5 & 4 & 3 & 3 & 3,5 \\
\hline 2. & Ahmad Hadi & 4 & 4 & 4,5 & 3 & 3,5 & 3 & 3 \\
\hline 3. & Sulastri & 3,5 & 3,5 & 4 & 3,5 & 3,5 & 3 & 3 \\
\hline
\end{tabular}

d. Perhitungan dan Pengelompokan

Core dan Secondary Factor Setelah menentukan bobot nilai gap untuk ketiga aspek yang dibutuhkan, kemudian tiap aspek dikelompokan lagi menjadi 2 kelompok yaitu core factor dan secondary factor. 
1. Core Factor (Faktor Utama)

Core factor merupakan aspek (kompetensi) yang paling menonjol/paling butuhkan oleh suatu kriteria yang diperkirakan dapat menghasilkan hasil yang optimal. Untuk menghitung core factor digunakan persamaan (1)

Page | 101

(1)

$$
N C F=\frac{\sum N C}{\sum I C}
$$

Keterangan :

$\mathrm{NCF}=$ Nilai rata-rata core factor aspek kapasitas intelektual

$\mathrm{NC}=$ Jumlah total nilai core factor aspek kapasitas intelektual

$\mathrm{IC}=$ Jumlah item core factor

\section{Secondary factor (Faktor Pendukung)}

Secondary factor adalah item-item selain aspek yang ada pada core factor. Untuk menghitung secondary factor digunakan persamaan (2)

(2)

$$
N S F=\frac{\sum N C}{\sum I S}
$$

Keterangan :

$\mathrm{NSF}=$ Nilai rata-rata secondary factor aspek kapasitas intelektual

$\mathrm{NS}=$ Jumlah total nilai secondary factor aspek kapasitas intelektual

IS = Jumlah item secondary factor Rumus diatas adalah rumus untuk menghitung core factor dan secondary factor dari aspek kapasitas intelektual.

Rumus diatas juga digunakan untuk menghitung core factor dan secondary factor dari aspek kelengkapan berkas dan aspek jaminan.

TABEL IV

CORE FACTORY DAN SECONDARY FACTORY DARI ASPEK KELENGKAPAN BERKAS

\begin{tabular}{|c|c|c|c|c|c|c|}
\hline \multirow{2}{*}{ No. } & \multirow{2}{*}{ Nama } & \multicolumn{3}{|c|}{$\begin{array}{c}\text { Aspek Kelengkapan } \\
\text { Berkas }\end{array}$} & \multirow{2}{*}{$\begin{array}{c}\text { Core Factory } \\
\text { NCF }=\frac{A+C}{2}\end{array}$} & $\begin{array}{c}\text { Secondary } \\
\text { Factory } \\
\text { NSF }=\text { B }\end{array}$ \\
\cline { 3 - 5 } & & $\mathrm{A}$ & $\mathrm{B}$ & $\mathrm{C}$ & & 4 \\
\hline 1. & Nurhayati & 3,5 & 4 & 4,5 & 4 & 4 \\
\hline 2. & Ahmad Hadi & 4 & 4 & 4,5 & 4,25 & 4 \\
\hline 3. & Sulastri & 3,5 & 3,5 & 4 & 3,75 & 3,5 \\
\hline
\end{tabular}

TABEL V

CORE FACTORY DAN SECONDARY FACTORY DARI ASPEK

\begin{tabular}{|c|c|c|c|c|c|c|c|}
\hline \multirow{2}{*}{ No. } & \multirow{2}{*}{ Nama } & \multicolumn{4}{|c|}{ Aspek Jaminan } & \multirow{2}{*}{$\begin{array}{c}\text { Core Factory } \\
\mathrm{NCF}=\frac{D+E+F+G}{4}\end{array}$} & \multirow{2}{*}{$\begin{array}{l}\text { Secondary } \\
\text { Factory } \\
\text { NSF }=\text {. }\end{array}$} \\
\hline & & $\mathrm{D}$ & E & $\mathrm{F}$ & $\mathrm{G}$ & & \\
\hline 1. & Nurhayati & 4 & 3 & 3 & 3,5 & 3,375 & 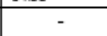 \\
\hline 2. & Ahmad Hadi & 3 & 3,5 & 3 & 3 & 3,125 & - \\
\hline 3. & Sulastri & 3,5 & 3,5 & 3 & 3 & 3,25 & - \\
\hline
\end{tabular}
JAMINAN

e. Perhitungan Nilai Total Tiap Aspek
Dari perhitungan core factor dan secondary factor dari tiap-tiap aspek, kemudian dihitung nilai total dari tiap-tiap aspek yang diperkirakan berpengaruh pada kinerja tiap-tiap profile. Untuk menghitung nila total dari masing- masing aspek, digunakan persamaan (3)

$N=X \% N C F+X \% N S F$

(3)

Keterangan :

$\mathrm{N}=$ Nilai Total Tiap Aspek

$\mathrm{NCI}=$ Nilai Core Factor

NSI $=$ Nilai Secondary Factor

$\mathrm{X} \%=$ inputan nilai persen dari sistem

Keterangan :

$\mathrm{N}=$ Nilai Total Tiap Aspek

$\mathrm{NCI}=$ Nilai Core Factor

NSI $=$ Nilai Secondary Factor

$\mathrm{X} \%=$ inputan nilai persen dari sistem

1. Aspek kelengkapan berkas berdasarkan persamaan 1 $\mathrm{N} 1=(60 \% \times \mathrm{NCF})+(40 \% \times \mathrm{NSF})$

TABEL VI

NILAI N1 DARI ASPEK KELENGKAPAN BERKA

\begin{tabular}{|c|c|c|c|c|}
\hline No. & Nama & CF & SF & Nl \\
\hline 1. & Nurhayati & 4 & 4 & 4 \\
\hline 2. & Ahmad Hadi & 4,25 & 4 & 4,15 \\
\hline 3. & Sulastri & 3,75 & 3,5 & 3,65 \\
\hline
\end{tabular}

2. Aspek jaminan berdasarkan persamaan 2 $\mathrm{N} 2=(60 \% \times \mathrm{NCF})+(40 \% \times \mathrm{NSF})$

TABEL VII

NILAI N2 DARI ASPEK JAMINAN

\begin{tabular}{|c|c|c|c|c|}
\hline No. & Nama & CF & SF & N2 \\
\hline 1. & Nurhayati & 3,375 & - & 2,025 \\
\hline 2. & Ahmad Hadi & 3,125 & - & 1,875 \\
\hline 3. & Sulastri & 3,25 & - & 1,95 \\
\hline
\end{tabular}

f. Rangking

Hasil akhir dari proses profile matching adalah rangking dari kandidat yang diajukan untuk mengisi suatu jabatan/posisi tertentu. Penentuan mengacu rangking pada hasil perhitungan yang ditujukan pada persamaan (4)

Rangking $=X \% N K I+X \% N S K+X \% N K P$

Keterangan :

NKI $=$ Nilai Aspek A

NSK $=$ Nilai Aspek B

$\mathrm{NKP}=$ Nilai Aspek C

$\mathrm{X} \%=$ inputan nilai persen dari sistem

Perhitungan Penentuan Rangking

Rangking $=(40 \% \times \mathrm{N} 1)+(60 \% \times \mathrm{N} 2)$ 
TABEL VIII

PERANGKINGAN DARI HASIL AKHIR

\begin{tabular}{|c|c|c|c|c|}
\hline No. & Nama & N1 & N2 & $\begin{array}{c}\text { Hasil } \\
\text { Akhir }\end{array}$ \\
\hline 1. & Nurhayati & 4 & 2,025 & 2,815 \\
\hline 2. & Ahmad Hadi & 4,15 & 1,875 & 2,785 \\
\hline 3. & Sulastri & 3,65 & 1,95 & 2,63 \\
\hline
\end{tabular}

Jadi, nasabah yang layak menerima pinjaman modal usaha ialah nasabah atas nama Nurhayati dengan nilai 2,815 .

\section{HASIL DAN PEMBAHASAN}

\section{A. Analisis Sistem}

Pada sistem pendukung keputusan kelayakan penerimaan nasabah menggunakan metode profile matching ini digunakan oleh karyawan. Karyawan dapat melakukan input data nasabah kedalam sistem dan sistem dapat memberikan laporan data penilaian nasabah ke karyawan. Kemudian sistem dapat memberikan laporan data penilaian nasabah ke Pimpinan perusahaan.

\section{Diagram Konteks}

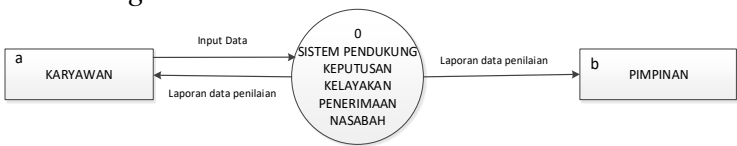

Gbr. 3 Diagram konteks Sistem Pendukung Keputusan Kelayakan Penerimaan Nasabah.

\section{Usecase Diagram}

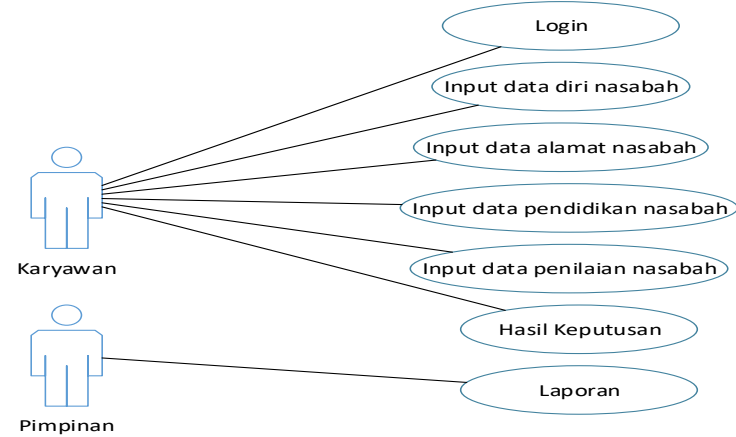

Gbr. 4 Usecase diagram

Karyawan melakukan login pada sistem pendukung keputusan kelayakaan penerimaan nasabah kemudian karyawan melakukan input data diri nasabah, input data alamat nasabah, input data pendidikan nasabah, dan input data penilaian nasabah. Setlah melakukan input data nasabah kedalam sistem, maka sistem dapat memberikan hasil keputusan yang dapat dilihat oleh karyawan. Kemudian dari hasil keputusan dibuatkan laporan dari karyawan ke pimpinan.

\section{Sequence Diagram}

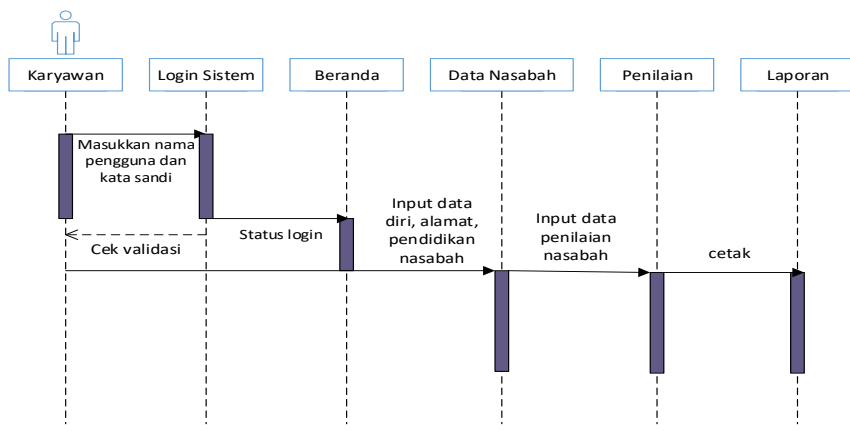

Gbr. 5 Sequence Diagram

Karyawan melakukan login sistem terlebih dahulu kedalam sistem dengan memasukan nama pengguna dan kata sandi kemudian masuk ditampilan beranda sistem terdapat 3 menu yaitu menu data nasabah, menu penilaiain, dan menu laporan. Pada menu data nasabah ialah mengisi data-data nasabah dan setelah terinput data nasabah maka menu penilaian dapat diisi, setelah terisi maka muncul hasil dari menu penilaian. Setelah menu penilaian memiliki data maka menu laporan dapat dibuat.

\section{B. Pengujian Sistem}

\section{Pengujian Perangkat Lunak}

Setelah pembuatan aplikasi telah selesai, maka dilakukan pengujian terhadap aplikasi. Dimana pengujian yang dilakukan pada apliksai yaitu pengujian fungsi sistem. Pengujian yang dilakukan pada fungsi sistem dengan menggunkan metode blackbox agar dapat mengetahui semua fungsi-fungsi sistem dapat berjalan dengan baik atau tidak.

Hasil pengujian fungsi sistem dapat dilihat pada tabel 9.

TABEL IX

TABEL PENGUJIAN FUNGSI SISTEM

\begin{tabular}{|c|c|c|c|}
\hline No. & $\begin{array}{l}\text { Fungsi Yang } \\
\text { Diuji }\end{array}$ & Ekspektasi Hasil & $\begin{array}{c}\text { Hasil } \\
\text { Pengujian }\end{array}$ \\
\hline 1. & \begin{tabular}{c|} 
Simpan Data \\
(Form Input Data \\
Nasabah)
\end{tabular} & Dapat menyimpan data nasabah & Baik \\
\hline 2. & $\begin{array}{l}\text { Ubah Data (Form } \\
\text { Ubah Data } \\
\text { Nasabah) }\end{array}$ & Dapat memperbaharui data nasabah & Baik \\
\hline 3. & \begin{tabular}{l|} 
Simpan Data \\
(Form Input Data \\
Penilaian)
\end{tabular} & Dapat menyimpan data penilaian & Baik \\
\hline 4. & $\begin{array}{l}\text { Data Nasabah } \\
\text { (Form data } \\
\text { nasabah) }\end{array}$ & $\begin{array}{l}\text { Dapat melihat data lengkap data } \\
\text { nasabah, }\end{array}$ & Baik \\
\hline 5. & $\begin{array}{c}\text { Data Penilaian } \\
\text { (Form Input data } \\
\text { penilaian) }\end{array}$ & $\begin{array}{l}\text { Dapat memasukan data penilaian dari } \\
\text { data nasabah sebelumnya }\end{array}$ & Baik \\
\hline 6. & $\begin{array}{c}\text { Laporan (Form } \\
\text { Laporan } \\
\text { kelayalkan } \\
\text { penerimaan } \\
\text { nasabah) } \\
\end{array}$ & $\begin{array}{l}\text { Dapat menampilkan nilai akhir, data } \\
\text { nasabah dan mencetak data laporan } \\
\text { kelayakan penerimaan nasabah }\end{array}$ & Baik \\
\hline 7. & $\begin{array}{l}\text { Masuk (Form } \\
\text { input nama } \\
\text { pengguna dan } \\
\text { kata sandi) }\end{array}$ & $\begin{array}{l}\text { Dapat masuk dengan memasukan nama } \\
\text { pengguna dan kata sandi dengan benar } \\
\text { dan tidak dapat masuk jika nama } \\
\text { pengguna dan kata sandi salah }\end{array}$ & Baik \\
\hline 8. & $\begin{array}{l}\text { Data Penilaian } \\
\text { (Form Data } \\
\text { Penilaian) }\end{array}$ & $\begin{array}{l}\text { Dapat melakukan proses perhitungan } \\
\text { metode Profile Matching dari data } \\
\text { penilaian }\end{array}$ & Baik \\
\hline
\end{tabular}




\section{Pembahasan}

Terdapat beberapa tahapan yang dilakukan dalam sistem pendukung keputusan kelayakan penerimaan nasabah yaitu:

1. Login

Menginputkan data nama pengguna dan kata sandi untuk masuk kedalam sistem.

Page | 103 2. Input Data Nasabah

Penginputan data nasabah didapat melalui data yang diperoleh langsung dari objek penelitian. Dimana sumber data yang diperlukan berasal dari PT. Sarana Sulteng Ventura Kota Palu. Data nasabah yang dimasukkan berupa data diri nasabah, data alamat nasabah, dan data Pendidikan nasabah.

3. Input Data Penilaian Nasabah

Penginputan data penilaian nasabah disesuai dengan nilai standar pada PT. Sarana Sulteng Ventura. Data penilaian dimasukkan sesuai dengan data yang diberikan oleh nasabah kemudian karyawan menginputkanya kedalam sistem dan diproses dengan menggunakan metode Profile Matching. Tahap tahap penghitungan nilai dengan menggunakan metode profile matching akan menggambungkan nilai setiap aspek kriteria dengan nilai nasabah. Untuk mendapatkan nilai akhir, ada beberapa langkah yang dilakukan. Menentukan nilai Gap untuk menjadi nilai standar, menentuknna nilai bobot Gap, mengelompokkan dan menghitung nilai core factor dan nilai secondary factor, menghitung nilai total dari setiap aspek, menghitung hasil rangking dan menentukan nilai akhir dari perhitungan nilai rangking tersebut.

4. Hasil Penilaian

Dengan perhitungan metode Profile Matching yang dilakukan oleh sistem maka data tersebut mengeluarkan hasil penilaian data nasabah yang dapat menentukan layak atau tidaknya nasabah diberikan pinjaman modal usaha.

5. Laporan

Nilai hasil penilaian keluar dari sistem maka karyawan dapat membuat laporan kelayakan penerimaan nasabah dan menyerahkan kepada Pimpinan.

\section{KESIMPULAN DAN SARAN}

\section{A. Kesimpulan}

Berdasarkan hasil pengujian dan analisis sistem pendukung keputusan kelayakan penerimaan nasabah menggunakan metode profile matching studi kasus pada PT. Sarana Sulteng Ventura Kota Palu, dapat disimpulkan bahwa :

1. Hasil penelitian yang dilakukan, sistem pendukung keputusan kelayakan penerimaan nasabah ialah dapat menentukan kelayakan penerimaan nasabah yang lebih cepat diproses oleh sistem, lebih efisien, dan tidak membutuhkan memori yang besar dalam penyimpanan data.

2. Metode profile matching adalah cara yang lebih efektif dalam menentukan keputusan kelayakan penerimaan nasabah dalam sistem tersebut.

\section{B. Saran}

Saran untuk penelitian dan pengembangan aplikasi selanjutnya mengingat masih banyaknya hal-hal yang belum dapat diimplementasikan pada penelitian ini, maka penulis berharap pembaca dapat mengkaji lebih dalam tentang metode profile matching sehingga dapat mengembangkan sistem pendukung keputusan dalam menggunakan metode lainya diantaranya metode $S A W, W P, A H P$ dan lain-lain.

\section{REFERENSI}

[1] A. Victor, C. F. Firmansyah, and T. Informatika, "Perangkat Lunak Pendukung Keputusan Calon Nasabah Pembiayaan Mikro Di Bank Syariah Mandiri Cabang Bandung Ahmadyani Menggunakan Metode Profile Matching," J. LPKIA, vol. 4, no. 1, pp. 1-5, 2014.

[2] M. Ickhsan, D. Anggraini, R. Haryono, S. H. Sahir, and Rohminatin, "Sistem Pendukung Keputusan Pemberian Kredit Usaha Rakyat ( KUR ) Menggunakan Metode Weighted Product," JURIKOM (Jurnal Ris. Komputer), vol. 5, no. 2, pp. 9-10, 2018

[3] M. Yusup, "Kredit Pada Nasabah Dengan Metode Simple Additive Weighting ( Studi Kasus Pt . Bprs Al Washliyah Medan )," Pelita Inform. Budi Darma, vol. 9, no. 2, pp. 182188, 2015.

[4] K. K. Kredit and M. Saw, "Sistem Pendukung Keputusan Kelayakan Pemberian Kredit Pada Pt. Adira Quantum Dumai Dengan Metode Simple Additive Weighting (Saw) Mengunakan Bahasa Pemograman Visual Basic 6.0," J. Inform., vol. 16, no. 1, pp. 1-9, 2016. 